\title{
Influencing Factors on Moral Licensing Effect: A Meta-Analytic Approach: An Abstract
}

\author{
Philipp Simbrunner and Bodo B. Schlegelmilch
}

\begin{abstract}
Moral licensing is a nonconscious effect that provides a moral boost in the self-concept, which increases the preference for a relative immoral action by dampening the negative self-attributions associated with such behavior. Applied to a marketing context, moral licensing explains why a purchase of a green product (a positive moral act) is likely to increase the likelihood of subsequently purchasing a luxury good (a negative moral act) or why donating to charity before purchasing a self-indulgent product increases the willingness to pay for this item. This study addresses the question which factors systematically influence the size of this effect by conducting a meta-analysis and meta-regressions. Results of a meta-regression analysis indicate that both cultural background and the type of comparison combined explain more than $20 \%$ of the total variation of moral licensing effect's size. For the first time, we demonstrate that moral licensing effect differs between culturally distinct regions, with higher effects in North American samples compared to Western Europeans. Moreover, in Southeast Asian samples, the effect is reversed in direction, meaning that performing a good deed increases the likelihood of doing good subsequently. Our results indicate that marketing measures building on this effect might lead to different revenues in different markets.
\end{abstract}

References Available Upon Request

P. Simbrunner $(\varangle) \bullet$ B.B. Schlegelmilch

Vienna University of Economics and Business, Vienna, Austria

e-mail: philipp.simbrunner@wu.ac.at; bodo.schlegelmilch@wu.ac.at

(C) Academy of Marketing Science 2018 